\title{
Wild Camels in Mongolia
}

\section{A. G. Bannikov}

Dr Bannikov, who is one of our FPS Consultants in the USSR, was recently decorated by the Soviet Government with the Order of the Red Banner of Labour for his work in nature conservation.

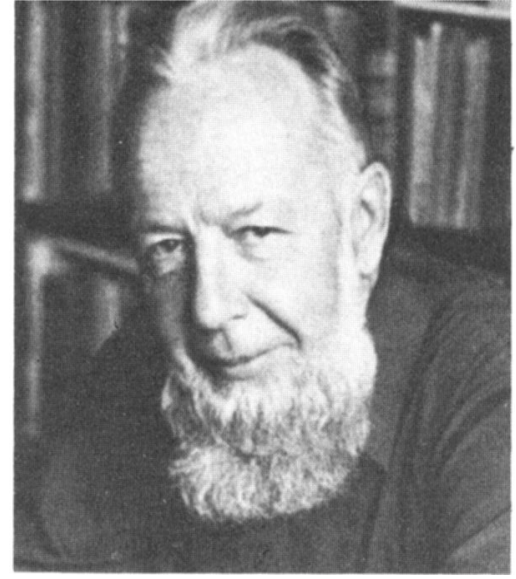

In August 1974, during a 600-km. journey across the Transaltaian Gobi of Mongolia, I made counts of wild ungulates including the wild camel, and collected data on their distribution, numbers and ecology. I discovered that the present range of the wild camel covers $40,000-45,000$ square kilometres, and has not changed radically since the 1940 s when I made my first investigations in the area. Only the southern part of their range, which lies chiefly within China, has been reduced. The expansion of the camels' area eastwards in the sixties, pointed out by the Mongolian zoologists D. Tsevegmid and A. Dashdorj (Oryx, XII, 3, 1974), turned out to be only accidental, temporary migrations. According to our data the total number of wild camels in Mongolia at present is about 900 .

Mongolia plans to establish the Gobi reserve covering about 4,000,000 hectares and including the greater part of the wild camels' area. This is an urgent measure deserving the support of international organisations, for the rapid development of the Gobi, and especially of oases, could result in a decrease or even extinction of the wild camels in their last and only refuge.

During the expedition Professor Bannikov took colour photographs of the wild camels which are the first of their kind. The photograph reproduced below in black and white is taken from one of these. 